\title{
Climate Warming-Related Strengthening of the Tropical Hydrological Cycle
}

\author{
MATTHIAS ZAHN AND Richard P. Allan \\ University of Reading, Reading, United Kingdom
}

(Manuscript received 19 April 2012, in final form 6 July 2012)

\begin{abstract}
The authors estimate climate warming-related twenty-first-century changes of moisture transports from the descending into the ascending regions in the tropics. Unlike previous studies that employ time and space averaging, here homogeneous high horizontal and vertical resolution data from an Intergovernmental Panel on Climate Change Fourth Assessment Report (IPCC AR4) climate model are used. This allows for estimating changes in much greater detail (e.g., the estimation of the distribution of ascending and descending regions, changes in the vertical profile, and separating changes of the inward and outward transports). Lowlevel inward and midlevel outward moisture transports of the convective regions in the tropics are found to increase in a simulated anthropogenically warmed climate as compared to a simulated twentieth-century atmosphere, indicating an intensification of the hydrological cycle. Since an increase of absolute inward transport exceeds the absolute increase of outward transport, the resulting budget is positive, meaning that more water is projected to converge in the moist tropics. The intensification is found mainly to be due to the higher amount of water in the atmosphere, while the contribution of weakening wind counteracts this response marginally. In addition the changing statistical properties of the vertical profile of the moisture transport are investigated and the importance of the substantial outflow of moisture from the moist tropics at midlevels is demonstrated.
\end{abstract}

\section{Introduction}

Future changes in the tropical hydrological cycle (Trenberth et al. 2007; Bengtsson 2010) may alter the distribution of available freshwater regionally through altered moisture transport properties and precipitation minus evaporation patterns (Allen and Ingram 2002; Trenberth et al. 2003). The atmospheric part of the hydrological cycle is to a large extent determined by the large-scale circulation patterns. In the tropics these consist of convective regions of upward, ascending air movement (ASC) and of regions of downward, descending air motion (DESC), with low-level flow into ASC and midlevel outflow into DESC commonly referred to as the Hadley cell circulation. Atmospheric moisture precipitates in ASC as air rises upward.

A key response in a warmed atmosphere is an increase of low-level atmospheric water vapor of $7 \%$ per degree of warming derived from theoretical considerations (the

Corresponding author address: Matthias Zahn, Environmental Systems Science Centre, University of Reading, Harry Pitt Building, 3 Earley Gate, Reading RG6 6AL, United Kingdom.

E-mail:m.zahn@reading.ac.uk
Clausius-Clapeyron relation; e.g., Wentz and Schabel 2000; Trenberth et al. 2003; Held and Soden 2006; O'Gorman and Muller 2010), with a strengthening impact on moisture transports and on precipitation. Precipitation generally has been found to increase with warming in the ascending tropical regions (Chou et al. 2007; John et al. 2009) and is expected to increase especially in extreme events, which were found to increase stronger than average (Kharin et al. 2007; Lenderink and van Meijgaard 2008; Allan and Soden 2008). However, models may have deficiencies representing the increase adequately (O'Gorman and Schneider 2009) and being in agreement with observations (Allan and Soden 2007; Allan et al. 2010). Over the course of the annual cycle Chou et al. (2007) found a precipitation increase in warm and wet seasons, but found the cooler dry seasons to become slightly drier as the atmosphere warms.

Generally climate warming-related changes of transported moisture are mainly explained by thermodynamic arguments (i.e., higher specific humidity in a warmer atmosphere), while the dynamic part (i.e. wind circulation) is generally considered less important (Emori and Brown 2005; Seager et al. 2010). Using different 
measures, a couple of studies have suggested that the tropical circulation part weakens (Vecchi et al. 2006; Power and Smith 2007; Gastineau and Soden 2009; Chou and Chen 2010). However, there have also been a couple of studies reporting the opposite, a strengthening of the circulation, at least in the past (Bigg 2006; Sohn and Park 2010; Zahn and Allan 2011).

Most of these studies are estimates based on lowresolution reanalysis data, low-resolution climate model data, or observation-based point measurements. Applying space- or time-averaged values was found to be insufficient in one of our recent studies (Zahn and Allan 2011) and may lead to wrong numbers for the moisture transport. We thus here reinvestigate climate warmingrelated changes of water vapor transports into the ascending regions of the tropics by applying high-resolution data from an Intergovernmental Panel on Climate Change Fourth Assessment Report (IPCC AR4) model. Unlike the methods in the above mentioned studies, we base our investigations not only on low-resolution time and/or spatial mean values but also on the 6-hourly output of the high horizontal and vertical resolution simulation.

\section{Data and method}

We used 6-hourly T213 $\left(0.5^{\circ}\right)$ horizontal resolution ECHAM5 model (Roeckner et al. 2003) data at 31 vertical levels representative for two time slices of 31 years, 1959-89 (C20) and 2069-99 (C21). The simulations are of the time slice type forced with boundary data (sea surface temperature and sea ice) from a coupled climate simulation with the same model at $\mathrm{T} 63$ resolution. The C20 uses observed greenhouse gas and aerosol forcing; the $\mathrm{C} 21$ forcing was delivered by the A1B scenario (Nakicenovic and Swart 2000) of the Fourth Assessment Report of the Intergovernmental Panel on Climate Change. We used vertical $(\omega)$ and horizontal $(\mathbf{U}, \mathbf{V})$ wind vectors, specific humidity $(q)$ and surface air pressure for all 31 model levels (from the surface up to the top of the atmosphere) in a two-staged approach for calculating the moisture transports, as follows:

- In model results of both C20 and C21, we first identified regions of ascending and of descending $\omega$ and defined the boundary separating both.

- In model results of both C20 and C21, we then identified $\mathbf{U}, \mathbf{V}$, humidity, and pressure at each level along the boundary and calculated the moisture transport. To do so humidity is transferred into precipitable water content (PWC) per level.

This method has been adapted from an earlier study applying reanalysis data (Zahn and Allan 2011) and is described in more detail in the following subsections.

\section{a. Definition of ascending and descending regions and of the boundary in between}

To define ascending and descending regions at each grid cell in the tropical region between $-30^{\circ}$ and $30^{\circ}$ latitude, the sum of the vertical wind motion $\omega$ of the lower and middle part of the atmosphere, the lowest 21 model levels corresponding to a height of up to approximately $450 \mathrm{hPa}$, was estimated. Before summing up, the vertical motion representative for each level is weighted by the thickness of each level. Grid boxes with an upward directed overall $\omega$ are assigned to the ascending region; otherwise, if $\omega=0$ or is directed downward they are assigned to the descending regions. The boundary over which moisture transports are estimated is defined as the line separating ASC and DESC. If ASC or DESC is cut by the $-30^{\circ}$ or $30^{\circ}$ latitude line, an artificial boundary is drawn along this latitude to avoid "open" regions.

ASC and DESC are estimated based on monthly mean $\omega$, resulting in 372 (one per month over 31 years) different ASC/DESC masks, as well as on instantaneous $\omega$ representative for the $180 \mathrm{~s}$ of the calculation time step in the ECHAM5 model, resulting in $\sim 45280$ (one per time step over 31 years) different ASC/DESC masks. Example fields of both are shown in Fig. 1. Please note that while the mean ASC/DESC masks reflect the general pattern of the intertropical convergence zone (ITCZ) with ASC stretching along the equator, the instantaneous field exhibits a much more complex pattern of convective cells and downdraft regions.

\section{b. Calculation of moisture transports}

At each time step $t$ the moisture transport is calculated across all the $n_{b}$ boundary segments $b$ between ASC and DESC (green lines in Fig. 1) at each of the $n_{l}$ vertical model levels $l$ by multiplying the perpendicular wind vector (WP) with the precipitable water content (PWC), respectively. The resulting total moisture transport (MT) per time step then reads

$$
\mathrm{MT}_{t}=\sum_{b}^{n_{b}} \sum_{l}^{n_{l}} \mathrm{WP}_{b l} \mathrm{PWC}_{b l} .
$$

Since applying mean wind speeds and mean PWC has proven to be insufficient previously (Zahn and Allan 2011), the calculations were only conducted using instantaneous variables. This leads to four experiments, moisture transports into monthly mean ascending regions (denoted $\mathrm{ASC}_{m}$ ) and into instantaneous ascending regions (denoted $\mathrm{ASC}_{i}$ ) for the twentieth and twentyfirst centuries, respectively. Please note that as a consequence of the four times daily instantaneous values, we 


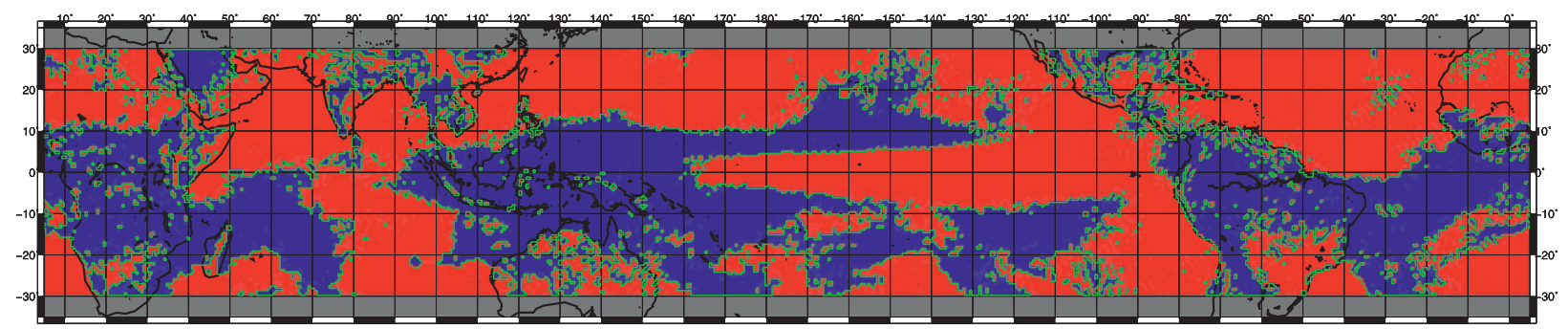

(a) $A S C_{m}$ Mar 1965

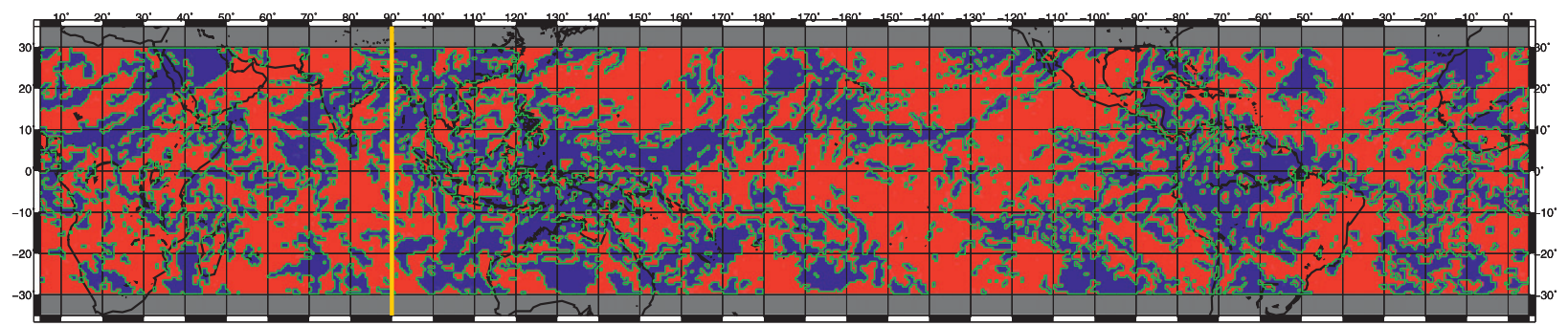

(b) $A S C_{i} 22$ Mar 1965, 6:00am

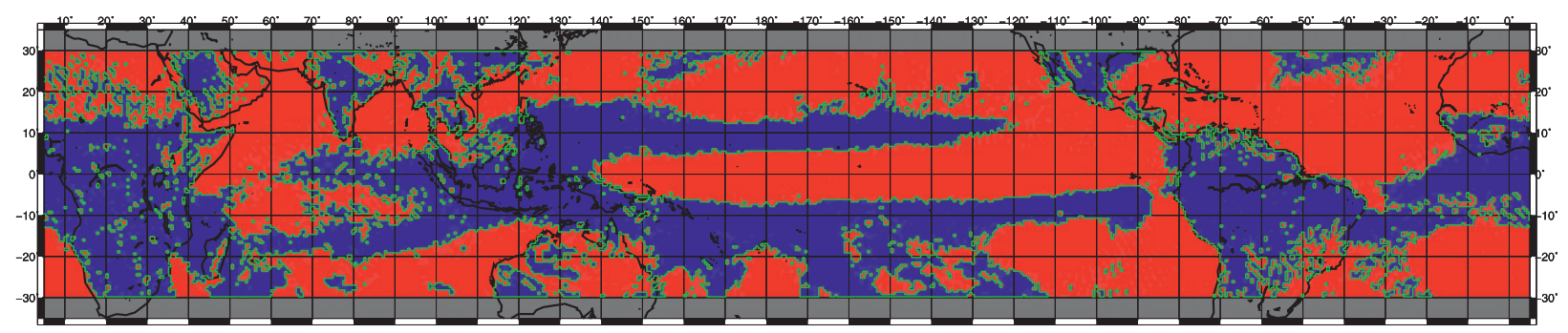

(c) $A S C_{m}$ Mar 2075

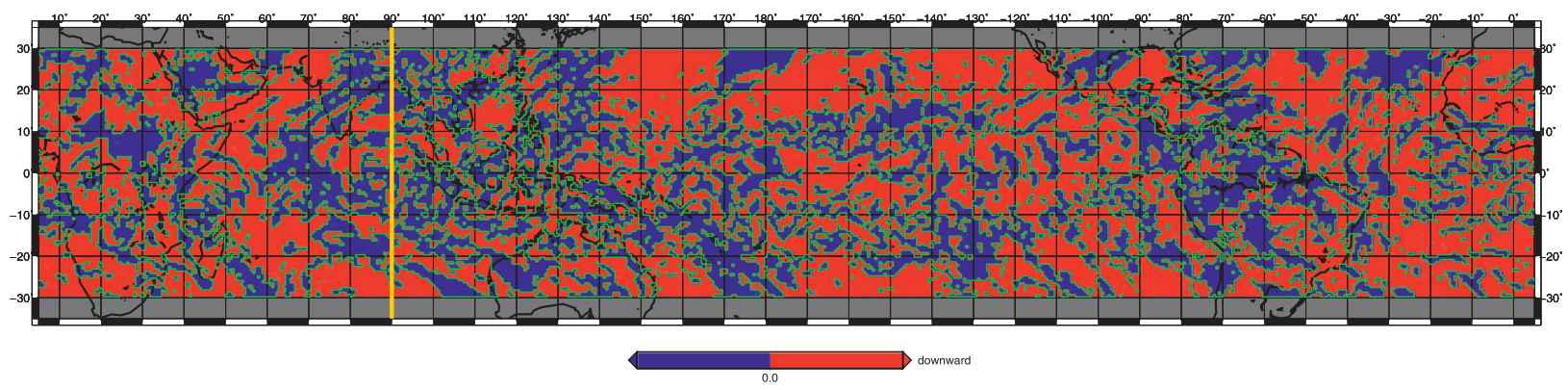

(d) $A S C_{i} 22$ Mar 2075, 6:00am

FIG. 1. Example fields of $\mathrm{ASC}_{i}$ and of $\mathrm{ASC}_{m}$ in $\mathrm{C} 20$ and $\mathrm{C} 21$. Distribution of ascending and descending regions from ECHAM5; red denotes downdraft, blue denotes updraft, and green is the boundary line across which fluxes are calculated. Data are valid for (a) March 1965, (b) 0600 UTC 22 Mar 1965, (c) March 2075 and (d) 0600 UTC 22 Mar 2075.

do not have a continuous integration of instantaneous moisture flux but rather a set of four observations per day. We should also note that in the C21 output the fields at three time steps, at 1200 UTC 18 January 2077 ,
1800 UTC 18 January 2077, and 1800 UTC 31 August 2079 were corrupt. They were replaced by the data at 0600 UTC 18 January 2077, 0000 UTC 19 January 2077, and 1200 UTC 31 August 2079, respectively. 


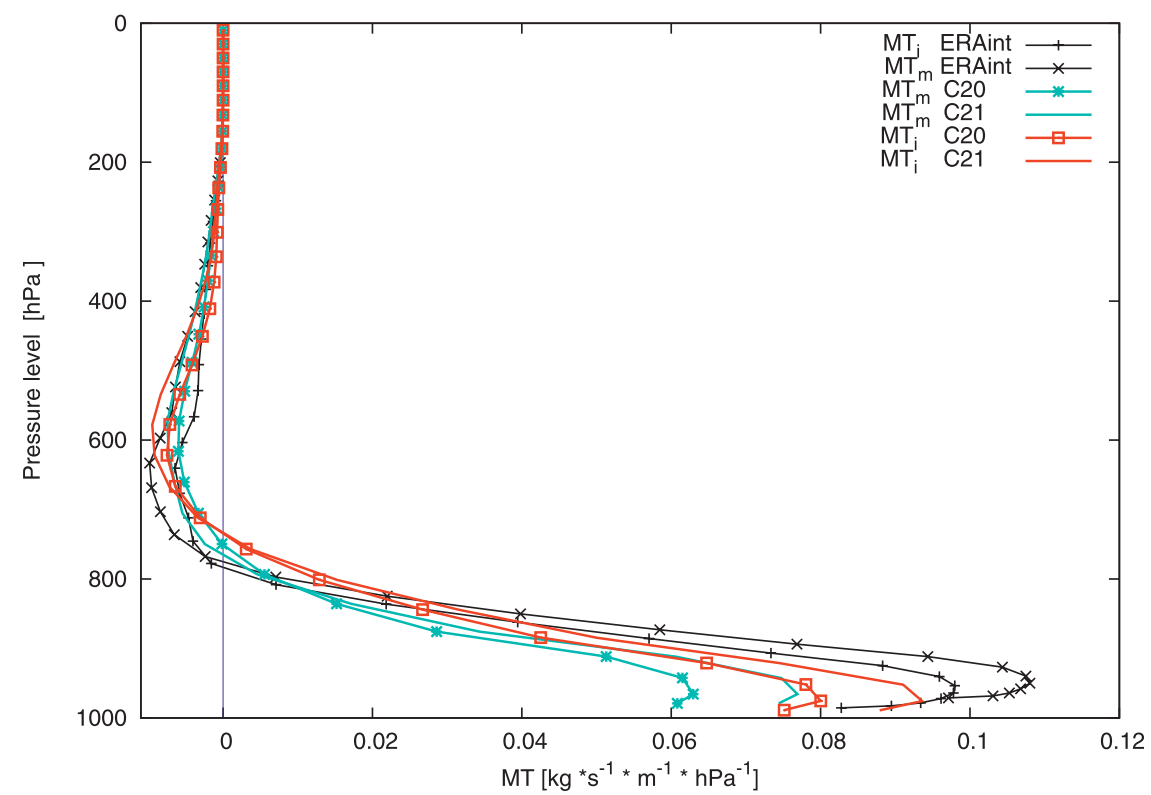

FIG. 2. Vertical profiles of horizontal moisture transports. Magnitude of horizontal net moisture transport per $\mathrm{hPa}$ along the ASC/DESC boundary from ECHAM5 and ERA-Interim (Dee et al. 2011; Zahn and Allan 2011) into $\mathrm{ASC}_{i}$ and $\mathrm{ASC}_{m}$. Positive/negative values denote net transports into/out of ASC. Symbols denote locations of mean pressure and mean transports. Note the unit of transport is $\mathrm{kg} \mathrm{s}^{-1} \mathrm{hPa}^{-1} \mathrm{~m}^{-1}$, with the vertical unit of the area given in pressure $(\mathrm{hPa})$.

\section{Results}

\section{a. Changes of the vertical profile of moisture transport}

The average vertical profile of transports along the boundary of ascending and descending regions in all experiments and in high-resolution reanalysis-based comparison data from the European Centre for MediumRange Weather Forecasts (ECMWF) Interim Re-Analysis (ERA-Interim; Dee et al. 2011; Zahn and Allan 2011) is dominated by a maximum of inward transports at the lower levels, but a considerable outward one (negative values) is visible as well above a certain reversal level (RL; Fig. 2), defined as the level at which moisture transport is $\mathrm{MT}=0$, and $\mathrm{MT}<0$ above and $\mathrm{MT}>0$ below. Despite a bias in the absolute numbers, the modeled profiles agree well with the reanalysis-based ones. All of them correspond well with expected moisture transports, which follow the Hadley circulation pattern and are directed toward ASC at the lower levels, and outwards at the midlevels. In the $\mathrm{ASC}_{m}$ as well as in the $\mathrm{ASC}_{i}$ experiments the inward moisture transports at the lower levels as well as the midlevel outflow are more intense in $\mathrm{C} 21$ than in $\mathrm{C} 20$.

Contrary to the idealized view of the Hadley circulation, the airflow is not directed toward the convective regions at all boundary segments at all times in the instantaneous wind fields, either in $\mathrm{ASC}_{i}$ or $\mathrm{ASC}_{m}$.
Rather, if isolated, inward and outward transport have a similar vertical shape (Fig. 3), which seems to be determined by the vertical distribution of moisture in the atmosphere. A weaker outward than inward transport at lower levels and, conversely, a stronger outward than inward transport at midlevels, results in the expected shape of the mean vertical profile.

Both ways of defining the convective regions $\left(\mathrm{ASC}_{m}\right.$ and $\mathrm{ASC}_{i}$ ) result in an increase of accumulated overall inward transport as well as in an increase of the accumulated overall outward transport of moisture (Table 1). The values transported into $\mathrm{ASC}_{i}$ are higher. The difference of these numbers in C21 and C20 is statistically significantly different from zero at the $99.5 \%$ level according to a $t$ test based on the instantaneous transports of all time steps. Although the increase of inward and outward directed transports counteracts the projected increase in the budget, it also is statistically significantly different from zero at the $99.5 \%$ level.

Based on the vertical profile we have separated the transports below RL and above, and calculated time series of the vertically aggregated yearly mean transports into ASC (positive values) below and of the vertically aggregated yearly mean transport out of ASC (negative values) above the reversal level in each of the experiments (Fig. 4). Like the total transports, both the lower-level inward and the midlevel outward transports 


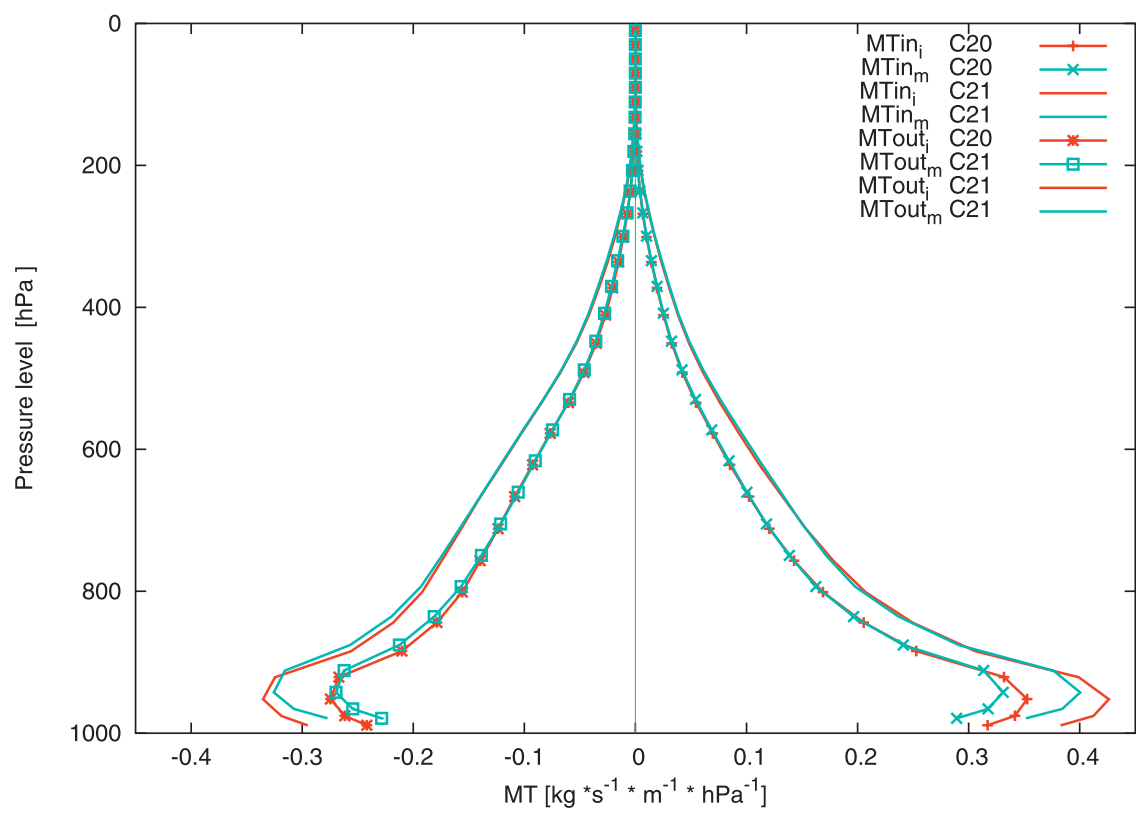

FIG. 3. Vertical profile of isolated inward and outward transport of moisture. Curves on the left (right) show the average vertical profile of isolated outward (inward) only transport of moisture per height [negative (positive) values] for the total period of the different experiments. Curves for $\mathrm{C} 20$ are denoted by lines with points; those for $\mathrm{C} 21$ are denoted by plain lines.

are projected to strengthen considerably in a warmed future. The change again is statistically significantly different from zero at $99.5 \%$ and results in an intensified hydrological cycle. The percentage increase of the outward transport above RL (Fig. $4 \mathrm{~b} ; \mathrm{MT}_{\text {out }} \approx 38 \%$ ) is more than twice as large as the inward transport below RL (Fig. $4 \mathrm{a} ; \mathrm{MT}_{\text {in }} \approx 17 \%$ ) in both experiments. This highlights the importance of the midlevel outward transports and that water from ASC may be recycled in DESC. Thus it may modify simplistic views on precipitation change in which precipitation in the moist tropics is assumed to scale with low-level tropospheric water vapor and thus basically with low-level moisture inflow only, as for example in Held and Soden (2006). The higher percentage increase in the outward moisture transport can be explained from theoretical considerations: following the Clausius-Clapeyron equation (Wentz and Schabel 2000; Held and Soden 2006), moisture content at the higher (and thus colder) levels experiences a higher percentage change than at the warmer lower levels (Allan 2012), which is in line with our data (Fig. 5).

Despite the increasing outward transports, a statistically significant increase is found for the budget $\left(\mathrm{MT}_{\mathrm{in}}-\right.$ $\mathrm{MT}_{\text {out }}$ ), which, assuming a negligible increase in total atmospheric water storage, determines the change of precipitation minus evaporation over the tropics. Thus, in line with previous studies (Wentz et al. 2007; Stephens and Ellis 2008; Allan et al. 2010; Liu and Allan 2012), tropical precipitation increases following our data. The contribution of moisture transports to this increase is about $15 \%$ from our $\mathrm{C} 20$ to $\mathrm{C} 21$ based on the absolute increase of the budget for both $\mathrm{ASC}_{i}$ and $\mathrm{ASC}_{m}$.

Additionally to a strengthening of the hydrological cycle from C20 toward C21, we also found an acceleration of the strengthening. Significant changes were not found for the $\mathrm{C} 20$ period, in accordance with simulations by ERA-Interim (Dee et al. 2011; Zahn and Allan 2011), but there is a statistically significant trend over the 31-yr C21 period (at the $99.5 \%$ level for the $\mathrm{ASC}_{i}$ budget and $97.5 \%$ for the $\mathrm{ASC}_{m}$ budget).

Previous studies (Wentz et al. 2007; Stephens and Ellis 2008; Allan et al. 2010) have suggested not only an

TABLE 1. Average of inward (MTin) and outward (MTout) moisture transport in C20 and C21. Values are based on instantaneous transports at all the $n_{b}$ boundary segments and all $n_{l}$ vertical levels at all time steps $t$ [cf. Eq. (1)]. To calculate the inward/ outward transport, transports at all boundary segments are used that are directed inward/outward of ASC (positive/negative curves in Fig. 3). Unit is $\mathrm{kg} \mathrm{s}^{-1} \mathrm{~m}^{-1}$.

\begin{tabular}{lccc}
\hline \hline & MTin & MTout & Budget \\
\hline $\mathrm{C} 20_{m}$ & 83.25 & -77.95 & 5.30 \\
$\mathrm{C} 21_{m}$ & 102.72 & -96.91 & 5.82 \\
$\mathrm{C} 20_{i}$ & 87.710 & -79.57 & 8.14 \\
$\mathrm{C} 21_{i}$ & 110.54 & -101.42 & 9.12 \\
\hline
\end{tabular}




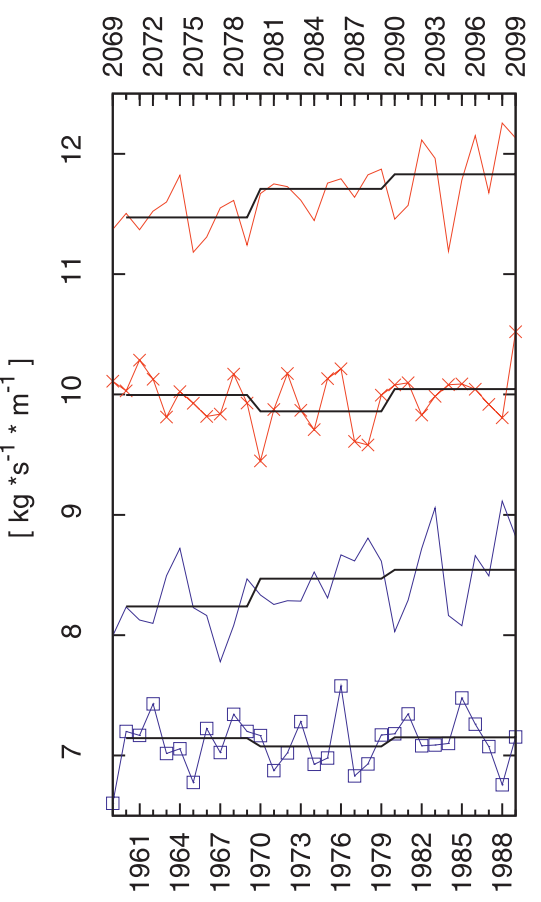

(a) $M T_{\text {in }}$

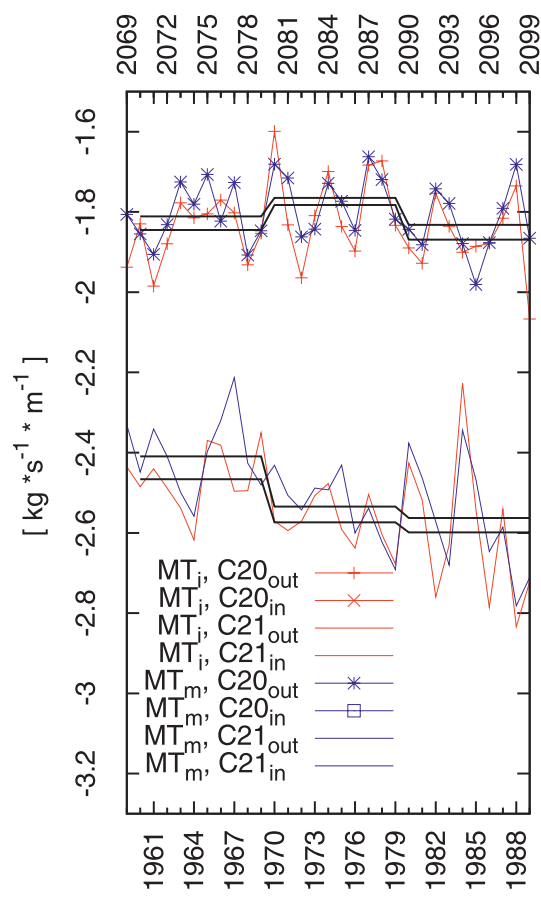

(b) $M T_{\text {out }}$

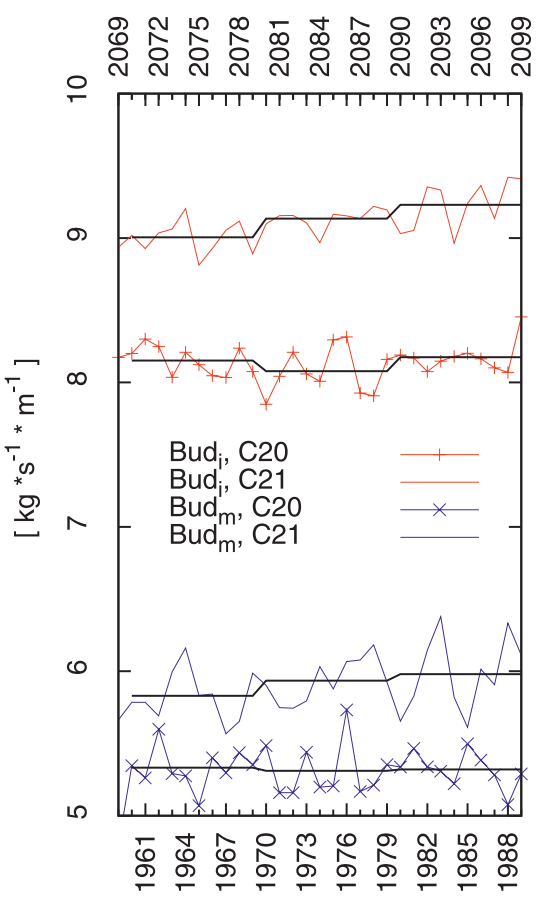

(c) Budget

FIG. 4. Temporal evolution of moisture transport into the ascending region. Time series of mean yearly moisture transports over ASC/ DESC boundary (a) below and (b) above the reversal level. (c) Time series of the yearly mean budget. C21 years are indicated by the upper $x$ axis; $\mathrm{C} 20$ years are indicated by the lower $x$ axis. Plain lines indicate $\mathrm{C} 21$ values; lines with symbols indicate $\mathrm{C} 20$ values. Flags for (a) are given in (b). Black lines indicate decadal means (first, second, and third decade of each dataset).

increase in the mean tropical precipitation as a response to a warmed atmosphere, but also a response in the higher percentiles of the distribution of precipitation events (Kharin et al. 2007; Allan and Soden 2008), commonly referred to as extreme events. To supply water for these events moisture transport must also have increased in the upper percentiles. The $x$ percentile is a threshold value above which $x \%$ of the observations (in our case simulated instantaneous moisture transports) are situated. We here used for each experiment the mean moisture transport over the boundary into $\mathrm{ASC}_{i}$ at each output time. Thus percentiles are calculated based on populations of more than 45000 observations (i.e., model time steps of $\mathrm{C} 20$ and C21; Figs. 6a,b). Their change over the projected century of warming is shown in Fig. 6c.

We find the most pronounced change in the highest percentiles of the low-level inward transport and of the midlevel outward transport (cf. large gaps between green and red line, which denotes the same $2 \%$ interval as the green and blue lines, respectively). The amount of increase of the strongest inward transport events (increase of the 99th percentile is $0.01629 \mathrm{~kg} \mathrm{~s}^{-1} \mathrm{~m}^{-1}$ ) is not counteracted by the same amount of outward transport (increase of the 99th percentile is $-0.00183 \mathrm{~kg} \mathrm{~s}^{-1} \mathrm{~m}^{-1}$ ), which is on the order of 10 times smaller. While there is a near-linear increase between the 20th and 80th percentiles, the upper end percentiles of moisture transport events increase at a greater rate (Fig. 7), resulting in greater precipitation rates during these extreme events.

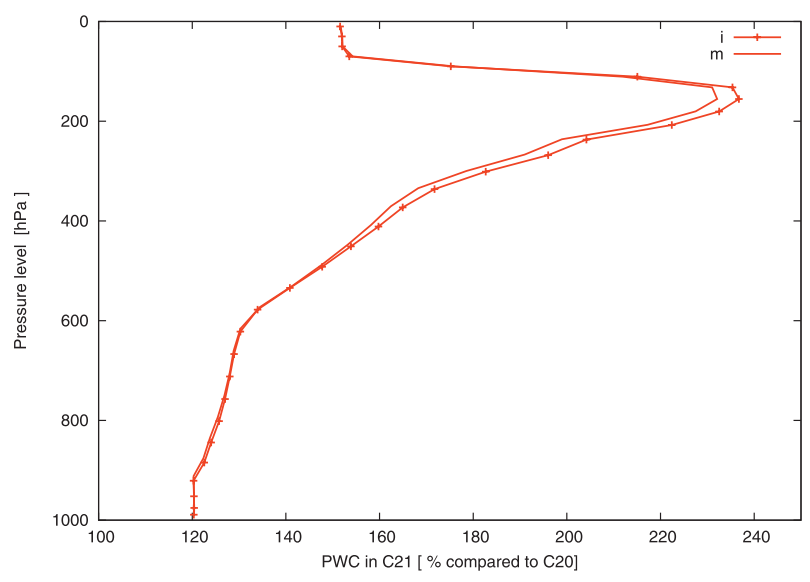

FIG. 5. PWC along boundaries in $\mathrm{C} 21$ relative to C20. Percentage of precipitable water content along the ASC/DESC boundary of $\mathrm{ASC}_{i}$ and $\mathrm{ASC}_{m}$ in $\mathrm{C} 21$ relative to $\mathrm{C} 20$. 


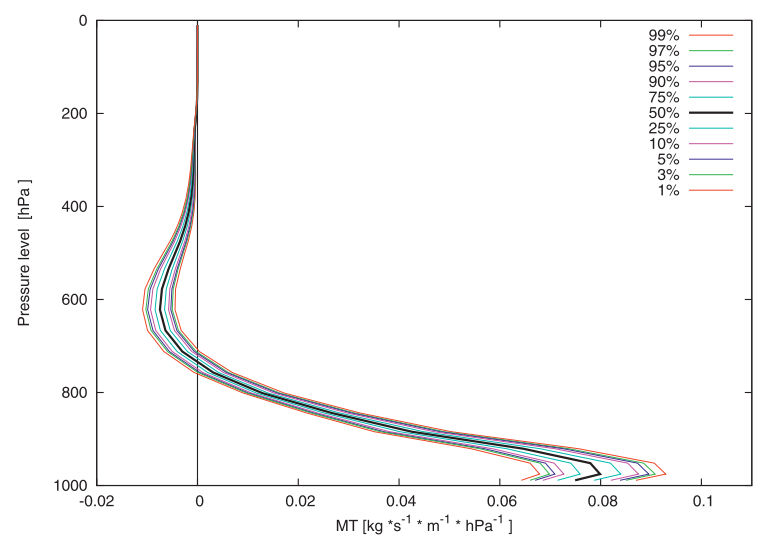

(a) $\mathrm{C} 20$

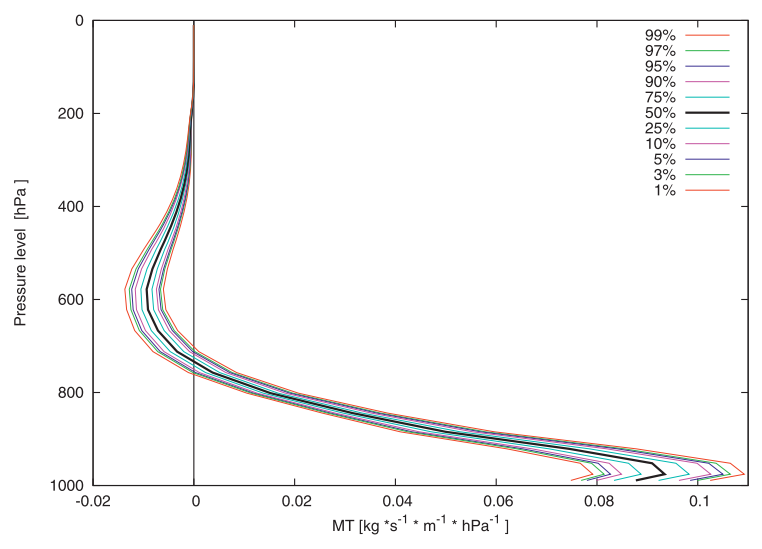

(b) $\mathrm{C} 21$

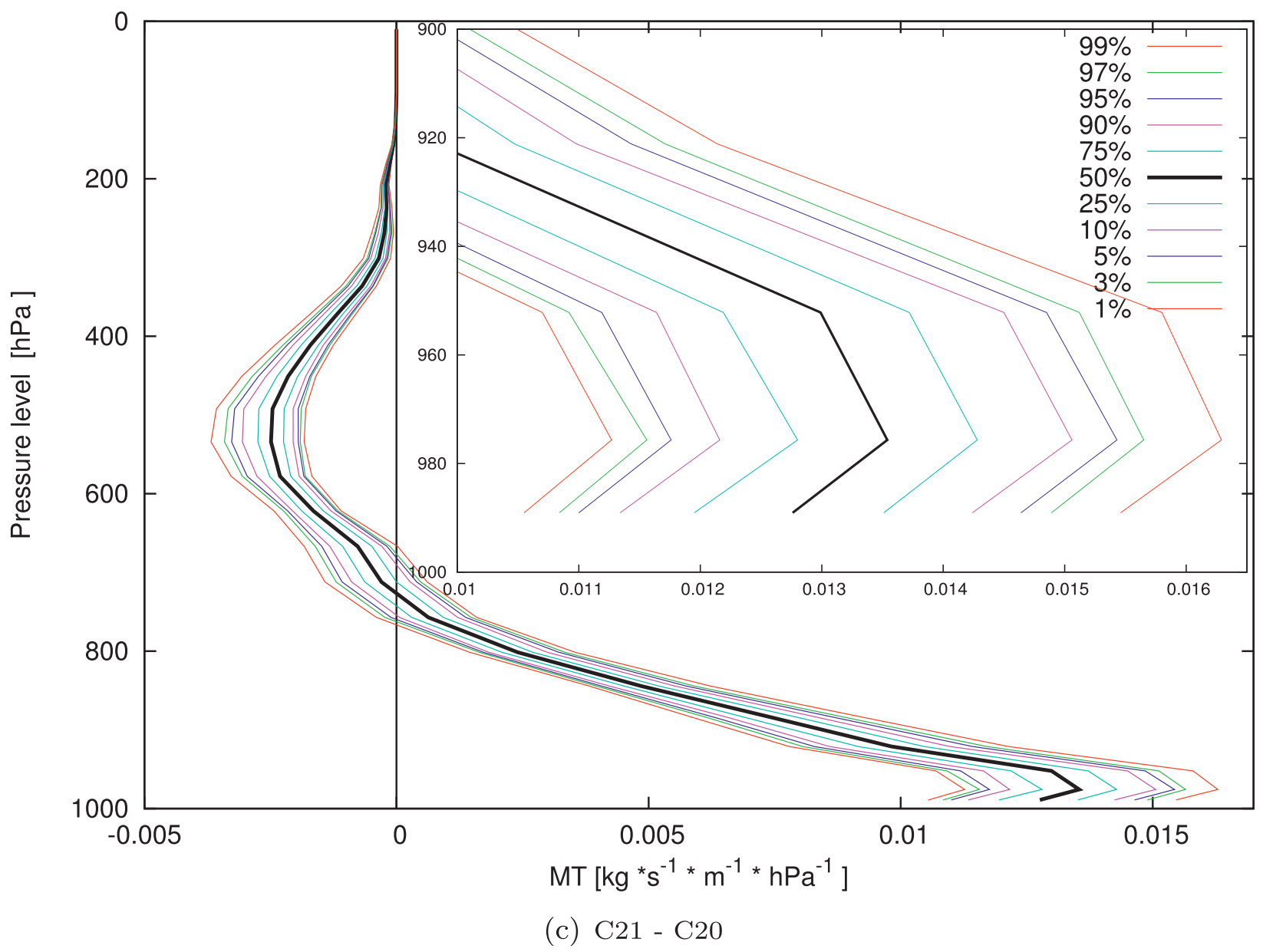

FIG. 6. Vertical structure of percentiles of moisture transports. Vertical structure of percentiles of moisture transports for (a) C20 and (b) C21. (c) Vertical profile of the difference between C21 and C20. Lower right corner is enlarged.

\section{b. Influence of changing wind and humidity}

The moisture transports depend on two measures, the wind vectors and the atmospheric water content along the border separating ASC and DESC. Consequently, changes in the transport are provoked by changes in either of these two measures. In line with the ClausiusClapeyron equation (Wentz and Schabel 2000; Held and Soden 2006), precipitable water has increased with warming throughout the atmosphere over all percentiles 


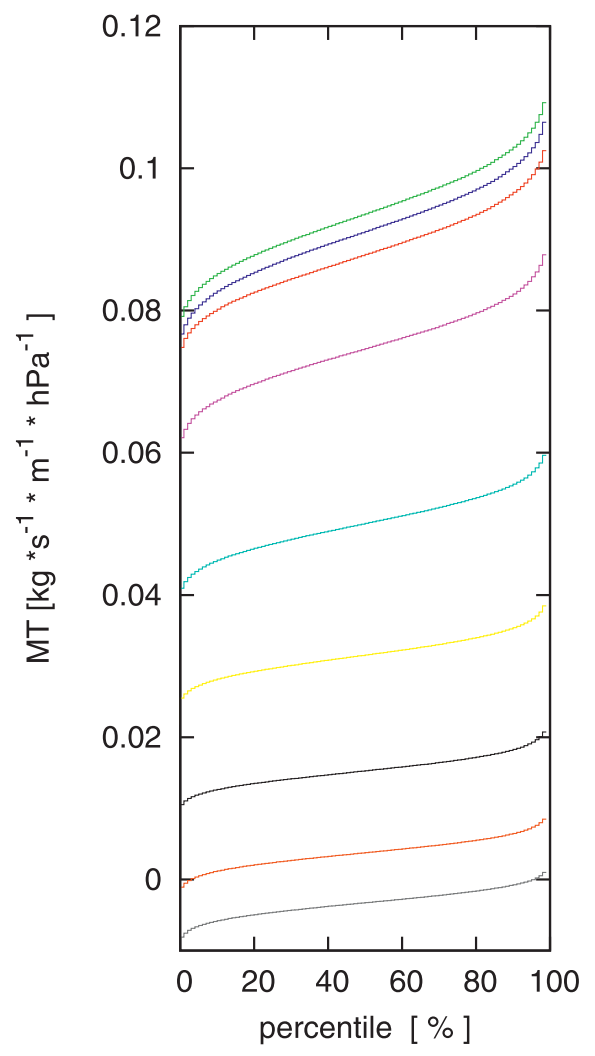

(a) $\mathrm{C} 21$

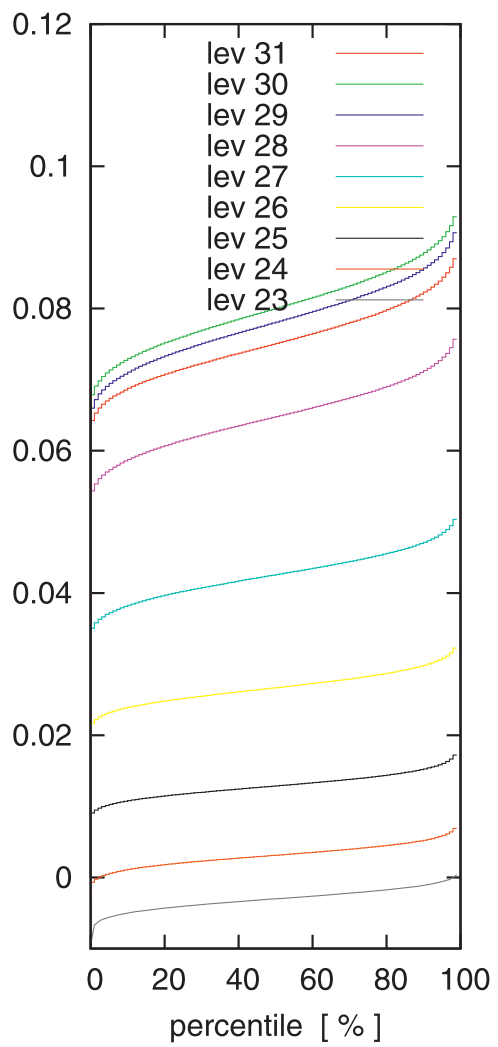

(b) $\mathrm{C} 20$

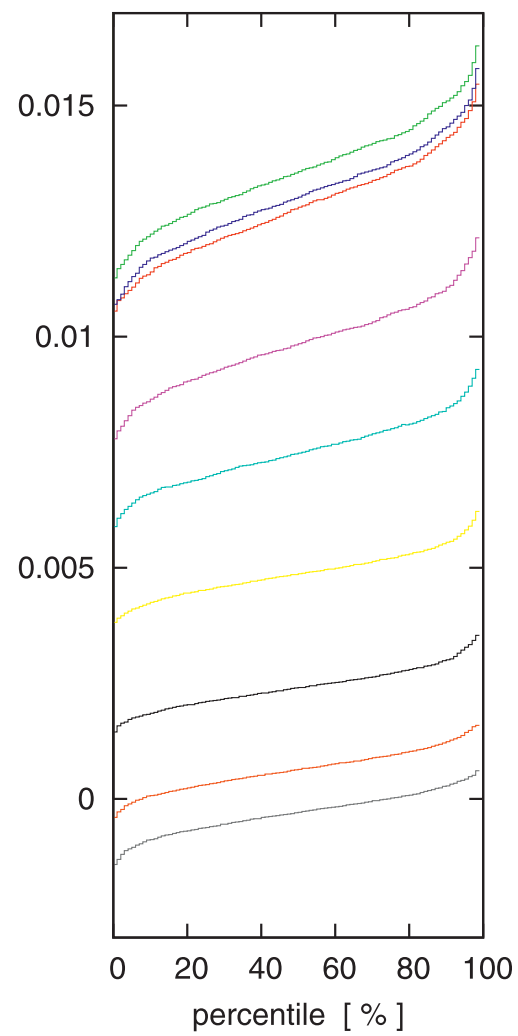

(c) $\mathrm{C} 21-\mathrm{C} 20$

FIG. 7. Percentiles of moisture transports at lower levels. (a) Percentiles of moisture transports at lower levels for C21, (b) percentiles of moisture transports at lower levels for $\mathrm{C} 20$, and (c) difference of percentiles of moisture transports at lower levels, C21 - C20. Colors of levels in (b) are also valid for (a) and (c).

(Fig. 8a) from $\mathrm{C} 20$ to $\mathrm{C} 21$. While the relative increase is stronger in the upper atmosphere (Fig. 5), the absolute amount of change is strongest at low levels, and decreases with height.

The situation is different for the wind. We here use a measure for the wind circulation strength independent from the actual level thickness and named "effective wind" previously (Sohn and Park 2010), which is the wind at a given level (between its upper and lower surface) weighted by the fraction of moisture held within this level. We found that for the lowerlevel inward transport below approximately $800 \mathrm{hPa}$, the effective wind is projected to weaken. Above $800 \mathrm{hPa}$ until about $600 \mathrm{hPa}$, at the vertical levels at which most of the outward transport takes place, the change is positive, meaning that a weakened wind contribution to the outward transport is projected. Only above this region, there are some levels projected to see an enhanced effective wind. We conclude that the projected increase of the strength of the hydrological cycle is caused by higher humidity rather than by circulation strength.

\section{c. Influence of northern and southern boundary of ASC}

The major part of the moisture is transported into ASC meridionally, following the lower branch of the Hadley circulation. Although some events occasionally are directed the opposite way, we find that this Hadley pattern is represented generally very well at our southern boundaries (Fig. 9). The situation at the northern boundary is more complex and the median $(50 \%$ percentile) is only slightly above 0 .

Generally the southern boundary inward transports dominate those at the northern boundary by far, which may be due to the distribution of land-sea mass across the globe. Northern boundaries of ASC are much more likely to be situated over land than the southern ones. Over land, however, air carries lower amounts of water due to lower supply by evaporation and circulation patterns are much more influenced by orography and thus much more complex (e.g., directed northward opposite the main flow even at low levels). Over the course of a warming twenty-first century a widening of the 


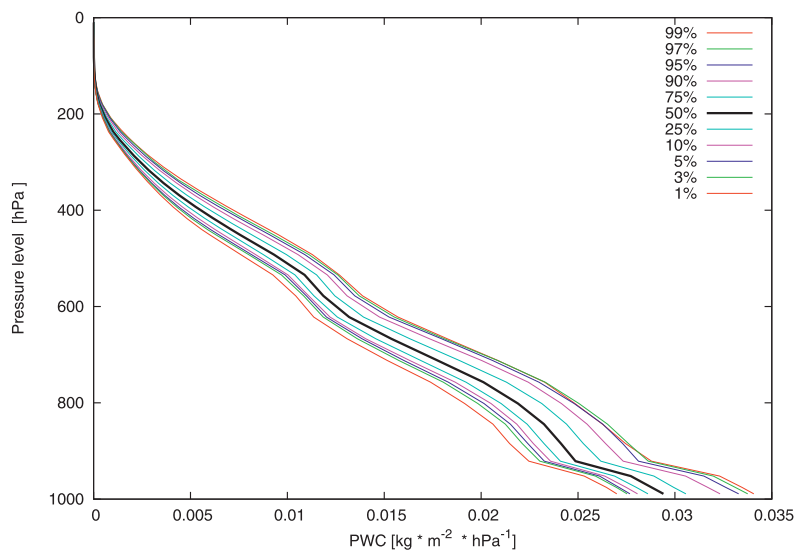

(a) PWC

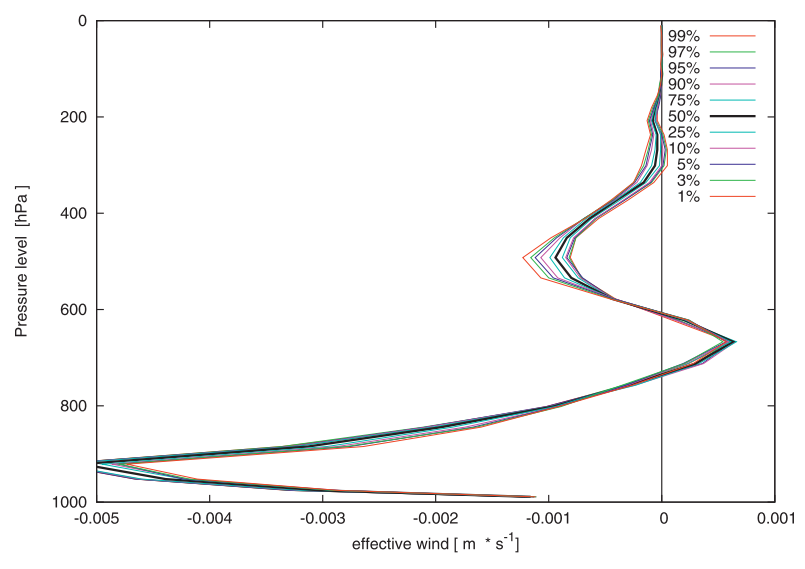

(b) effective wind

FIG. 8. Changes of percentiles of precipitable water and of effective wind along boundary of convective regions; Vertical profiles of differences in the percentiles of (a) precipitable water and (b) effective wind (C21 - C20). Here, effective wind is the mean wind directed toward ASC at a given level, weighted by the water content at the same level relative to the total column water content, following the definition of Sohn and Park (2010).

percentiles of lower-level inward and outward transport events (recall that instantaneous transports do not always follow the idealized vertical shape of the Hadley circulation) are observed at both the northern and the southern boundary. However, the median only increases (by almost a quarter) at the southern boundary, whereas the already low value at the northern boundary gets even smaller. Thus, the domination of the southern boundary for the moisture transports into ASC increases.

\section{d. Changes of ASC/DESC pattern}

There may be an influence of the latitude ASC is located at since regions closer to the equator are normally warmer and thus air does carry more moisture here, allowing for larger moisture transports. We found large changes of the frequency a particular grid box belongs to $\mathrm{ASC}$ in the two experiments, $\mathrm{ASC}_{i}$ and $\mathrm{ASC}_{m}$, with minor changes in few areas only (white in Fig. 10a). The changes are about 3 times more distinct for $\mathrm{ASC}_{m}$. Along the equatorial oceans there exists an area of increasing likelihood to belonging to ASC, indicating more frequent convection. North and south of this are some areas, especially in $\mathrm{ASC}_{m}$ (Fig. 10b), with less frequent upward vertical wind velocity. This suggests a narrowing of the ITCZ in these regions, shifting their borders equatorward to warmer latitudes and enhancing the transports in addition to the already warming atmosphere. This narrowing becomes more obvious when the zonal mean frequencies of a grid box belonging to ASC are examined (Figs. 10c,d). For $\mathrm{ASC}_{i}$, the ASC/ DESC pattern is not very distinct, and there are few changes visible from $\mathrm{C} 20$ toward $\mathrm{C} 21$. For $\mathrm{ASC}_{m}$ a distinct ASC/DESC pattern is visible. If one assumes a certain threshold to separate dry and moist regions in the tropics (e.g., moist grid boxes must belong to the ASC more than $40 \%$ of the time), there is a narrowing of the ITCZ. A narrowing of the ITCZ does not necessarily oppose the findings of a widening of the Hadley cell by Lu et al. (2007) and Previdi and Liepert (2007), since they use a different measure and estimate the latitude of maximum downdraft (streamfunction is zero) in the dry subtropics. However, it highlights the sensitivity of any measure to the methods applied. A narrowing may even be in line with the "upped-ante mechanism" proposed before, in which relatively dry low-level advection into the ITCZ (Lintner and Neelin 2007) may lead to an inward shift of the margins of the convective regions (Chou et al. 2009).

There are major areas of less frequent ascending air movement over the Indonesian islands, the updraft region of the Walker circulation. Associated with the Walker circulation is a downdraft of air masses over the tropical Pacific. Our findings suggest a weakening of the Walker circulation, with less frequent convection in its updrafting and more frequent convection in its downdrafting branch in a warmed atmosphere, in line with previous studies (Vecchi et al. 2006; Merlis and Schneider 2011), and with a weakening of zonal tropical circulations with warming in general (Vecchi and Soden 2007).

\section{Discussion}

In this study we investigate changing tropical moisture transports associated with future climate warming. We used data from a high space and time $\left(0.5^{\circ}, 6 \mathrm{~h}\right)$ resolution IPCC AR4 model. As done in most studies applying 


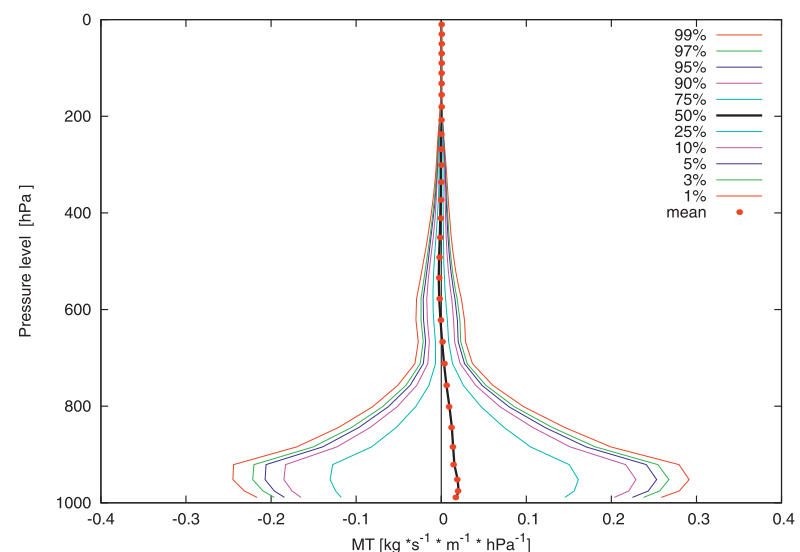

(a) at northern boundary, C20

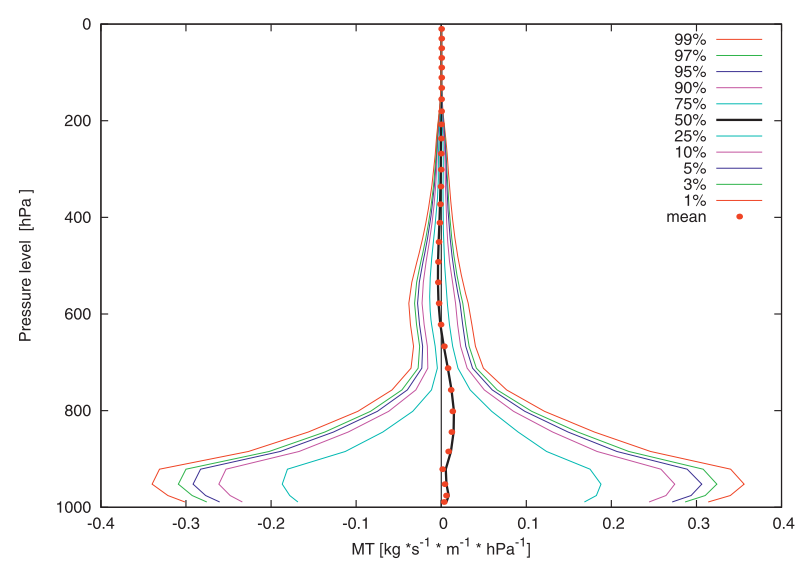

(c) at northern boundary, C21

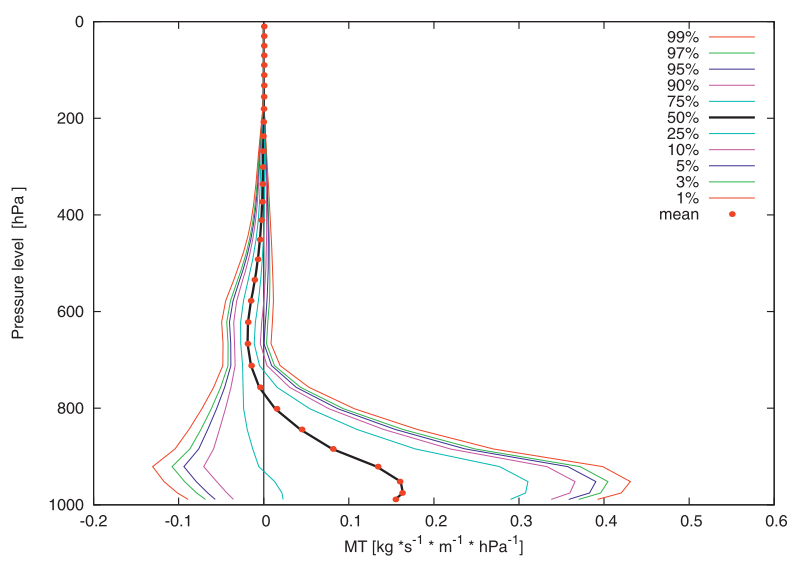

(b) at southern boundary, C20

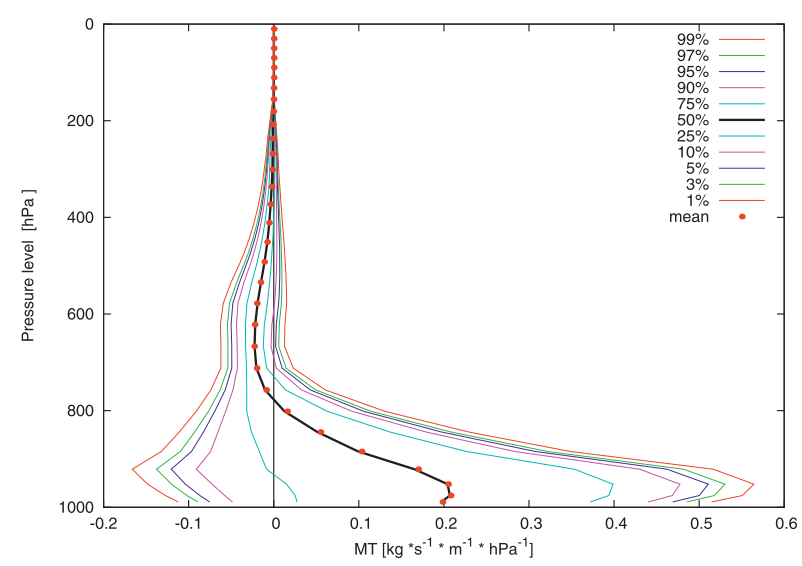

(d) at southern boundary, C21

FIG. 9. Vertical structure of percentiles of moisture transports at northern and southern boundaries of ASC $i$, at (a) the northern boundary in $\mathrm{C} 20$, (b) the southern boundary in C20, (c) the northern boundary in C21, and (d) the southern boundary in C21. Also given is the mean transport per hPa, respectively.

mean data, we estimated moisture transports into mean regions of air ascent, representative of regions referred to as the moist tropics or the ITCZ. However, our highresolution data also enabled us to calculate instantaneous moisture transports into individual convective regions. In doing so we link instantaneous vertical wind with instantaneous humidity and horizontal wind, which is physically more consistent than linking mean and instantaneous variables.

This may be illustrated by the transports for the example field in Fig. 1. When the instantaneous wind and humidity field of 0600 UTC 22 March 1965 is applied to $\mathrm{ASC}_{m}$ of March, most of the boundary segments of $\mathrm{ASC}_{m}$ would not overlap with those of the instantaneous field. This means that most of the $\mathrm{ASC}_{m}$ boundary segments are not at the margins of the actual $\mathrm{ASC}_{i}$, which are physically consistent with the distribution of instantaneous wind and humidity, but instead separate two DESC or two ASC grid boxes of the instantaneous field. As a consequence, instantaneous moisture transports applied to $\mathrm{ASC}_{m}$ do not represent transports from DESC to ASC, but would be calculated from wet to wet or from dry to dry grid boxes, and maybe even from wet to dry, but not from dry to wet along many of the boundary segments. We consider that such physically inconsistent mixing of mean and instantaneous values to calculate transports leads to the systematically different values in between the two experiments.

Using the high horizontal and vertical resolution data allowed us to investigate moisture transports at very high detail. The moisture budget of a region is determined by the inward and outward transports, which together constitute the circulation pattern. To fully understand changes of the moisture budget, changes of 


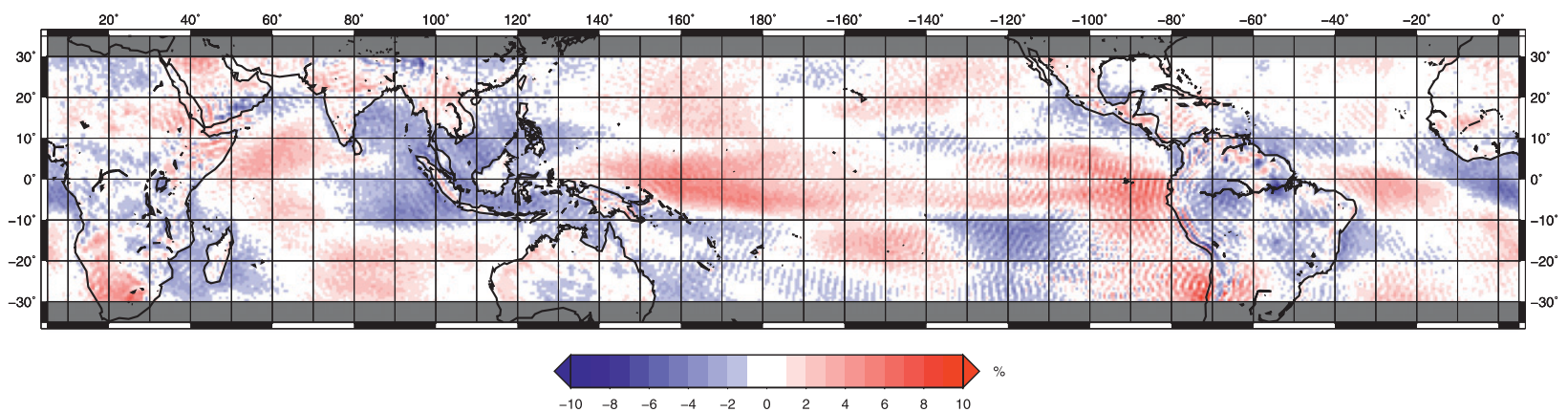

(a) $A S C_{i}$

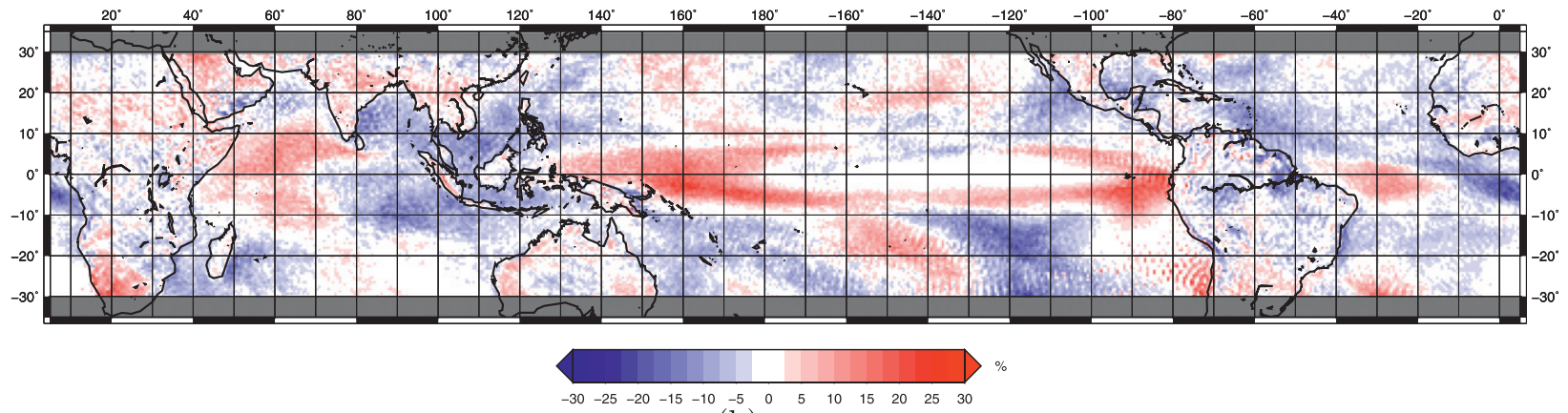

(b) $A S C_{m}$

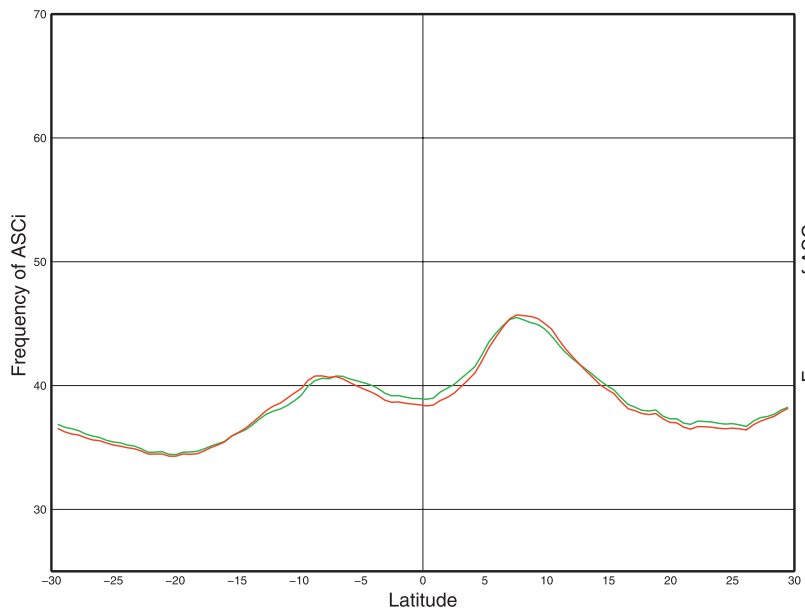

(c) zonal mean $A S C_{i}$

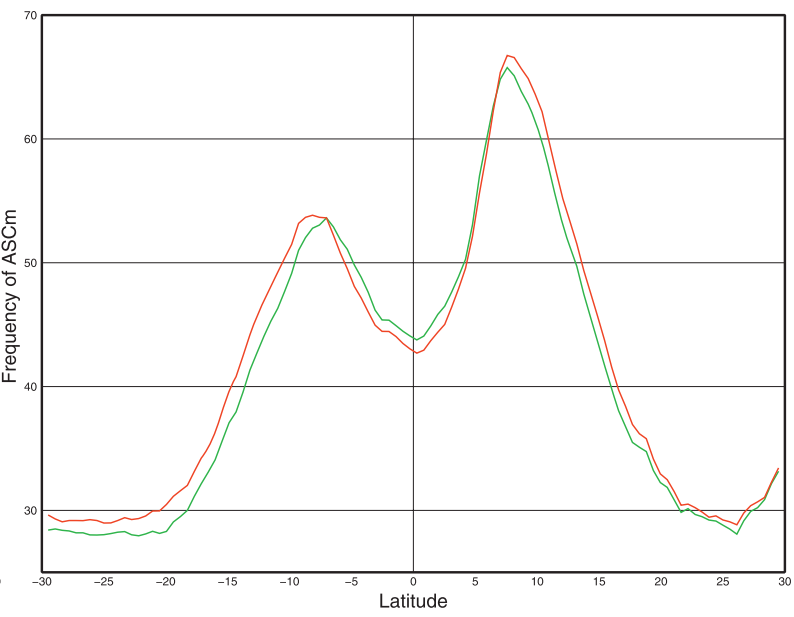

(d) zonal mean $A S C_{m}$

FIG. 10. Changing frequency of the ascending regions. (a) Change of percentage of time steps a grid box belongs to ASC from the instantaneous vertical wind $\left(\mathrm{ASC}_{i}\right), \mathrm{C} 21-\mathrm{C} 20$. (b) Change of percentage a grid box belongs to ASC when derived from the monthly mean vertical wind $\left(\mathrm{ASC}_{m}\right), \mathrm{C} 21-\mathrm{C} 20$. Red indicates a box belongs to ASC more frequently; blue means it belongs to ASC less frequently. Note the different scale of the color bar. (c),(d) Zonal mean percentage a grid box belongs to $\mathrm{ASC}_{i}$ and $\mathrm{ASC}_{m}$, respectively. Green denotes $\mathrm{C} 21$ and red $\mathrm{C} 20$.

the inward and outward transports of moisture need to be understood. Here we can differentiate between lower-level inward and midlevel outward transports and find both to have intensified, especially during extreme precipitation events. It has been found in recent studies that changes of the amount of precipitation from models do not scale well with observed ones (Allan and Soden 2007; Allan et al. 2010). Modeled increases in precipitation were found to be too weak in ASC, but the observed decline in DESC was too weak as well. One may speculate that models overestimate the midlevel outward transports, which leads or at least contributes to 
such behavior. This may be caused by too high humidity values at the midlevels due to too weak moist convection parameterization schemes in the tropics, which may not "rain out" enough of the atmospheric water. Different convection schemes have been suggested to cause large intermodel spread for precipitation scaling (O'Gorman and Schneider 2009). However, it cannot be verified that midlevel humidity values are too high at this point since comprehensive 3D humidity observations for the atmosphere are not available.

Unlike previous studies for the recent past, which found the influence of humidity change to be of minor and the wind contribution to be of higher importance (Sohn and Park 2010; Zahn and Allan 2011), we here found the opposite for a projected future change. Moisture transport changes are mainly found to be due to higher atmospheric humidity values, and not to changing wind characteristics, which were rather found to have weakened. However, the two reanalysis based studies span relatively short time periods only with small temperature increases and the signal of change may be influenced by short-term variability.

A somewhat surprising finding is a narrowing of the ITCZ in our data, since previous studies have suggested a widening of the Hadley cell (Lu et al. 2007; Previdi and Liepert 2007). A straightforward assumption would have been a widening of the ITCZ as well. However, our results use a different measure and are only based on one model and are not statistically significant yet, but we think it would be interesting to investigate this in more detail.

Even more surprising is the fact that applying the same data we get different answers whether the ITCZ has expanded depending on if we apply instantaneous or temporally averaged vertical wind. The different changes may be explained by a non-Gaussian distribution of vertical wind speeds (Emori and Brown 2005). Grid cells, which are frequented by strong convective cells (with high upward $\omega$ ) only at a few time steps are rarely assigned to $\mathrm{ASC}_{i}$, but will be assigned to $\mathrm{ASC}_{m}$ when the upward $\omega$ at these few situations is greater than the otherwise low-intensity downdraft situations in the averaging. One may speculate that some extremely intensive convective cells from more intense tropical storms in a warmed atmosphere (Bengtsson et al. 2007; Knutson et al. 2010) may cause the differently pronounced change between $\mathrm{ASC}_{i}$ and $\mathrm{ASC}_{m}$.

\section{Summary}

We demonstrate, using high time and space resolution simulations, a strengthening of the water exchange into and out of the ascending regions of the tropics with climate warming, consistent with an intensified hydrological cycle. This is valid for the lower-level inward transport as well as for the midlevel outward one. The response is particularly pronounced for the highest percentiles of moisture transport, indicating an intensification in the extremes of precipitation. The changes are mainly caused by higher atmospheric humidity values, and the wind contribution has a minor dampening effect. Finally we show that averaging data may lead to different results on changes in the ITCZ.

Acknowledgments. The simulations were performed with the ECHAM5 model developed at the Max-Planck Institute for Meteorology, Germany, at HLRN (Norddeutscher Verbund für Hoch- und Höchstleistungsrechnen). We are thankful to Noel Keenlyside and Kevin Hodges for help with these data and for discussions. M.Z. was funded by the NERC PREPARE project, NE/G015708/1.

\section{REFERENCES}

Allan, R. P., 2012: The role of water vapour in earth's energy flows. Surv. Geophys., 33, 557-564.

, and B. J. Soden, 2007: Large discrepancy between observed and simulated precipitation trends in the ascending and descending branches of the tropical circulation. Geophys. Res. Lett., 34, L18705, doi:10.1029/2007GL031460.

- and _ 2008: Atmospheric warming and the amplification of precipitation extremes. Science, 321, 1481-1484.

,-- , V. O. John, W. Ingram, and P. Good, 2010: Current changes in tropical precipitation. Environ. Res. Lett., 5, 025205, doi:10.1088/1748-9326/5/2/025205.

Allen, M. R., and W. J. Ingram, 2002: Constraints on future changes in climate and the hydrologic cycle. Nature, 419, 224-232.

Bengtsson, L., 2010: The global atmospheric water cycle. Environ. Res. Lett., 5, 025202, doi:10.1088/1748-9326/5/2/025202.

_ K. I. Hodges, M. Esch, N. Keenlyside, L. Kornblueh, J.-j. Luo, and T. Yamagata, 2007: How may tropical cyclones change in a warmer climate? Tellus, 59, 539-561, doi:10.1111/ j.1600-0870.2007.00251.x.

Bigg, G. R., 2006: Comparison of coastal wind and pressure trends over the tropical Atlantic: 1946-1987. Int. J. Climatol., 13, 411421, doi:10.1002/joc.3370130405.

Chou, C., and C.-A. Chen, 2010: Depth of convection and the weakening of tropical circulation in global warming. J. Climate, 23, 3019-3030.

_ J. Tu, and P. Tan, 2007: Asymmetry of tropical precipitation change under global warming. Geophys. Res. Lett., 34, L17708, doi:10.1029/2007GL030327.

- J. D. Neelin, C.-A. Chen, and J.-Y. Tu, 2009: Evaluating the "rich-get-richer"mechanism in tropical precipitation change under global warming. J. Climate, 22, 1982-2005.

Dee, D. P., and Coauthors, 2011: The ERA-Interim reanalysis: Configuration and performance of the data assimilation system. Quart. J. Roy. Meteor. Soc., 137, 553-597, doi:10.1002/ qj. 828 .

Emori, S., and S. J. Brown, 2005: Dynamic and thermodynamic changes in mean and extreme precipitation under changed 
climate. Geophys. Res. Lett., 32, L17706, doi:10.1029/ 2005 GL023272.

Gastineau, G., and B. J. Soden, 2009: Model projected changes of extreme wind events in response to global warming. Geophys. Res. Lett., 36, L10810, doi:10.1029/2009GL037500.

Held, I. M., and B. J. Soden, 2006: Robust responses of the hydrological cycle to global warming. J. Climate, 19, 5686-5699.

John, V. O., R. P. Allan, and B. J. Soden, 2009: How robust are observed and simulated precipitation responses to tropical ocean warming? Geophys. Res. Lett., 36, L14702, doi:10.1029/ 2009GL038276.

Kharin, V. V., F. W. Zwiers, X. Zhang, and G. C. Hegerl, 2007: Changes in temperature and precipitation extremes in the IPCC ensemble of global coupled model simulations. $J$. Climate, 20, 1419-1444.

Knutson, T. R., and Coauthors, 2010: Tropical cyclones and climate change. Nat. Geosci., 3, 157-163, doi:10.1038/ngeo779.

Lenderink, G., and E. van Meijgaard, 2008: Increase in hourly precipitation extremes beyond expectations from temperature changes. Nat. Geosci., 1, 511-514, doi:10.1038/ngeo262.

Lintner, B. R., and J. D. Neelin, 2007: A prototype for convective margin shifts. Geophys. Res. Lett., 34, L05812, doi:10.1029/ 2006GL027305.

Liu, C., and R. P. Allan, 2012: Multi-satellite observed responses of precipitation and its extremes to interannual climate variability. J. Geophys. Res., 117, D03101, doi:10.1029/2011JD016568.

Lu, J., G. A. Vecchi, and T. Reichler, 2007: Expansion of the Hadley cell under global warming. Geophys. Res. Lett., 34, L06805, doi:10.1029/2006GL028443.

Merlis, T. M., and T. Schneider, 2011: Changes in zonal surface temperature gradients and Walker circulations in a wide range of climates. J. Climate, 24, 4757-4768.

Nakicenovic, N., and R. Swart, Eds., 2000: Special Report on Emissions Scenarios. Cambridge University Press, 612 pp.

O'Gorman, P. A., and T. Schneider, 2009: The physical basis for increases in precipitation extremes in simulations of 21stcentury climate change. Proc. Natl. Acad. Sci. USA, 106, $14773-14777$.

-, and C. J. Muller, 2010: How closely do changes in surface and column water vapor follow Clausius-Clapeyron scaling in climate change simulations? Environ. Res. Lett., 5, 025207, doi:10.1088/1748-9326/5/2/025207.
Power, S. B., and I. N. Smith, 2007: Weakening of the Walker circulation and apparent dominance of El Niño both reach record levels, but has ENSO really changed? Geophys. Res. Lett., 34, L18702, doi:10.1029/2007GL030854.

Previdi, M., and B. G. Liepert, 2007: Annular modes and Hadley cell expansion under global warming. Geophys. Res. Lett., 34, L22701, doi:10.1029/2007GL031243.

Roeckner, E., and Coauthors, 2003: The atmospheric general circulation model ECHAM 5. Part I: Model description. MPI Rep. 349, 127 pp. [Available online at http://www.mpimet.mpg.de/ fileadmin/publikationen/Reports/max_scirep_349.pdf.]

Seager, R., N. Naik, and G. A. Vecchi, 2010: Thermodynamic and dynamic mechanisms for large-scale changes in the hydrological cycle in response to global warming. J. Climate, $\mathbf{2 3}$, 4651-4668.

Sohn, B. J., and S.-C. Park, 2010: Strengthened tropical circulations in past three decades inferred from water vapor transport J. Geophys. Res., 115, D15112, doi:10.1029/2009JD013713.

Stephens, G. L., and T. D. Ellis, 2008: Controls of global-mean precipitation increases in global warming GCM experiments. J. Climate, 21, 6141-6155.

Trenberth, K. E., A. Dai, R. M. Rasmussen, and D. B. Parsons, 2003: The changing character of precipitation. Bull. Amer. Meteor. Soc., 84, 1205-1217.

— L. Lmith, T. Qian, A. Dai, and J. Fasullo, 2007: Estimates of the global water budget and its annual cycle using observational and model data. J. Hydrometeor., 8, 758-769.

Vecchi, G. A., and B. J. Soden, 2007: Global warming and the weakening of the tropical circulation. J. Climate, 20, 43164340.

- - A. T. Wittenberg, I. M. Held, A. Leetmaa, and M. J. Harrison, 2006: Weakening of tropical Pacific atmospheric circulation due to anthropogenic forcing. Nature, 441, 73-76, doi:10.1038/nature04744.

Wentz, F. J., and M. Schabel, 2000: Precise climate monitoring using complementary satellite data sets. Nature, 403, 414-416, doi:10.1038/35000184.

_ - L. Ricciardulli, K. Hilburn, and C. Mears, 2007: How much more rain will global warming bring? Science, 317, 233-235.

Zahn, M., and R. P. Allan, 2011: Changes in water vapor transports of the ascending branch of the tropical circulation. J. Geophys. Res., 116, D18111, doi:10.1029/2011JD016206. 